 Beds Revealed in High-Point-Density Airborne Laser Scanning Data
}

\author{
Guo-Hao Huang, Chi-Kuei Wang, Fu-Chun Wu, and Peter M. Atkinson
}

\begin{abstract}
5 Abstract-The aim of this study was to examine the relation6 ship between the anisotropy direction of exposed gravel bed and 7 flow direction. Previous studies have shown that the anisotropy 8 direction of a gravel bed surface can be visually determined in the 9 elliptical contours of $2-D$ variogram surface (2DVS). In this letter, 10 airborne laser scanning (ALS) point clouds were acquired at a 11 gravel bed, and the whole data set was divided into a series of $126 \mathrm{~m} \times 6 \mathrm{~m}$ subsets. To estimate the direction of anisotropy, we 13 proposed an ellipse-fitting-based automatic procedure with con14 sideration given to the grain size characteristic $d_{50}$ to estimate the 15 primary axis of anisotropy [hereafter referred to as the primary 16 continuity direction (PCD)] in the 2DVS. The ALS-derived PCDs 17 were compared to the flow directions (for both high and low 18 flow) derived from hydrodynamic model simulation. Comparison 19 of ALS-derived PCDs and simulated flow directions suggested that 20 ALS-derived PCDs could be used to infer flow direction at differ21 ent flow rates. Furthermore, we found that the ALS-derived PCDs 22 estimated from any elliptical contour of the 2DVS exhibited a simi23 lar orientation when the contours of the 2DVS reveal the clear an24 isotropic structure, demonstrating the robustness of the technique.
\end{abstract}

25 Index Terms-Airborne laser scanning (ALS), flow direction, 26 spatial continuity, 2-D variogram surface (2DVS).

\section{INTRODUCTION}

28

in $\mathbf{T}$ HE geostatistical variogram function has been recognized as an important tool for detecting spatial anisotropy in 31 different variables, such as air pollution [1], snow depth [2], and 32 exposed gravel bed structures [3]-[8]. The anisotropy indicates 33 that the spatial correlation pattern changes with orientation, 34 and it can be represented by the elliptical contours in a 2-D 35 variogram surface (2DVS).

36 Many studies have shown that the visually determined 37 anisotropy direction of a 2DVS can be associated with different 38 mechanisms, such as wind for air pollution and snow depth 39 structures [1], [2] and hydrodynamic dispersion (i.e., flow

Manuscript received November 8, 2015; revised March 16, 2016 and April 11, 2016; accepted April 27, 2016.

G.-H. Huang and C.-K. Wang are with the Department of Geomatics, National Cheng Kung University, Tainan 70101, Taiwan (e-mail: chikuei@ mail.ncku.edu.tw).

F.-C. Wu is with the Department of Bioenvironmental Systems Engineering, National Taiwan University, Taipei 10617, Taiwan.

P. M. Atkinson is with the Department of Geography and Environment, University of Southampton, SO17 1BJ Southampton, U.K., with the Faculty of Science and Technology, Lancaster University, Lancaster LA1 4YW, U.K., with the Faculty of Geosciences, University of Utrecht, 3584 Utrecht, The Netherlands, and also with the School of Geography, Archaeology and Palaeoecology, Queen's University, Belfast BT7 1NN, U.K.

Color versions of one or more of the figures in this paper are available online at http://ieeexplore.ieee.org.

Digital Object Identifier 10.1109/LGRS.2016.2562061 movement) for homogeneous porous media [9]. In the last two 40 decades, substantial studies have investigated the anisotropy 41 directions derived from a 2DVS in the exposed gravel beds and 42 suggested that the anisotropy directions exhibited in the gravel 43 bed surfaces reflect the dominant grain orientation [3]-[6]. 44 Various studies have examined the relationship between gravel 45 orientation and flow direction [10]-[16]. For lower flows, larger 46 pebbles, and lower pebble concentrations, elongated pebbles 47 are transported by rolling and are deposited with their major 48 axes normal to the flow direction. For higher flows, smaller 49 pebbles, and higher pebble concentrations, the pebbles skip 50 along the bed and tend to be deposited with their major axis 51 parallel to the flow [16]. It has been reported that particle 52 imbrication would occur naturally in a direction parallel to 53 the flow [5], [16], [17]. Particle imbrication covering a range 54 of directions might indicate that flow direction changed over 55 the duration of the last competent event (e.g., varied with 56 flow depth) or that different flows (with different directions) 57 imbricated particles in different ways over time [16]. It has 58 also been reported that the anisotropy directions failed at being 59 conclusive on the surface-forming flow direction [5], [18]. The 60 latter is notoriously difficult to determine accurately from in situ 61 visual observations [19].

The determination of flow direction is essential to trace the 63 water paths and sediment transportation. For coarse bed materi- 64 als, rolling/sliding and saltation are the most possible modes of 65 sediment transport, with rolling/sliding dominated by coarser 66 pebbles and saltation dominated by finer gravel. Alignment 67 of bed particles transverse to the flow can be associated with 68 transport mode by rolling and sliding [17], while bed structure 69 longitudinal to the flow can be attributed to deposition of 70 saltating particles after contact with the upstream front of stable 71 grain and particle imbrications [4], [5], [20]. It is thus of interest 72 to explore the relationship between the anisotropy of gravel 73 bed surfaces and flow direction across large areas. However, 74 comparison of anisotropy direction determined visually from 75 a 2DVS, extracted for laboratory and field gravel surfaces, to 76 flow direction determined from subjective observation [3]-[6] 77 revealed no common consensus about the relationship between 78 anisotropy direction and flow movement in exposed gravel 79 beds. This is possibly due to the limited numbers of data and 80 the small spatial extents available to earlier researchers.

Advances in remote sensing have facilitated the measurement 82 of gravel bed surfaces in a spatially extensive and cost-effective 83 way based on the airborne approach, including airborne laser 84 scanning (ALS), aerial photogrammetry, and unmanned aerial 85 systems (UASs) [8], [21]-[23]. Huang and Wang [8] have 86 indicated that a detailed description of gravel bed surfaces is 87 
88 a prerequisite for visualizing the obvious anisotropy pattern in 89 the 2DVS of gravel bed surfaces. Recent progress on combining 90 UAS and structure-from-motion photogrammetry has gained 91 attention for measuring submerged and dry gravel beds, and 92 it has been shown that a digital elevation model (DEM) with 93 a spatial resolution of a few centimeters can be achieved [22], 94 [23]. However, the UAS has to be operated at a low altitude 95 (i.e., lower than $100 \mathrm{~m}$ ) for such a purpose, and this would be 96 challenging when performing UAS surveys in river valleys. The 97 ALS, which incorporates laser ranging, inertial measurement 98 unit, and Global Positioning System technologies, has shown 99 potential for mapping the surface elevation of a large area [24]. 100 Moreover, the pulse repetition frequencies of the commercial 101 ALS systems have increased from $70 \mathrm{kHz}$ in 2003 (as for the 102 ALS used in this study) to $900 \mathrm{kHz}$ in 2014 [25], which shows 103 that the ALS is now economically favorable for capturing 104 gravel bed surfaces with high-density ALS point clouds.

105 In this research, we examined the anisotropy characteristics 106 of a very high-point-density ALS data of an exposed gravel 107 bed by comparing its anisotropy direction with simulated flow 108 directions under high- and low-flow scenarios based on fixed109 bed hydrodynamic modeling. To better reveal the variation of 110 the anisotropy characteristic within the river channel, the whole 111 ALS data set was divided into a series of $6 \mathrm{~m} \times 6 \mathrm{~m}$ subsets, 112 which results in 324 subsets of ALS point data. In order to 113 consistently derive the anisotropy direction for each $6 \mathrm{~m} \times 6 \mathrm{~m}$ 114 subset, we devised an ellipse-fitting-based automatic procedure 115 with the consideration of the grain size characteristic $d_{50}$, which 116 is the median of particle size distribution, to determine the 117 primary axis of anisotropy [hereafter, referred to as the primary 118 continuity direction (PCD)] in the 2DVS.

\section{9}

\section{METHOD}

\section{A. 2DVS}

121 The variogram has been used widely to quantify the spatial 122 variability in gravel bed surfaces [4], [5], [8]. The empirical 123 variogram, which is half the mean squared difference between 124 pairs of data points separated by the lag vector $\mathbf{h}$, can be 125 expressed as

$$
\hat{\gamma}(\mathbf{h})=\frac{1}{2 N(\mathbf{h})} \sum_{i=1}^{N(\mathbf{h})}\left[z\left(\mathbf{x}_{i}\right)-z\left(\mathbf{x}_{i}+\mathbf{h}\right)\right]^{2}
$$

126 where $\hat{\gamma}(\mathbf{h})$ is the semivariance, the lag (distance and direction) 127 vector $\mathbf{h}$ is the separation between two data points, $N(\mathbf{h})$ is the 128 number of point pairs separated by lag $\mathbf{h}$, and $z\left(\mathbf{x}_{i}\right)$ is the bed 129 elevation at the location $\mathbf{x}_{i}$.

130 The empirical variogram is a function that relates semivari131 ance $\hat{\gamma}(\mathbf{h})$ to lag $\mathbf{h}$ and is usually expressed as a set of 1-D plots, 132 where different plots represent different directions. An alterna133 tive is to plot all directions together as a 2DVS, i.e., a raster map 134 of semivariance values $\hat{\gamma}\left(\mathbf{h}_{x}, \mathbf{h}_{y}\right)$ representing the empirical 135 variogram for all available lag vectors $\mathbf{h}=\left(\mathbf{h}_{x}, \mathbf{h}_{y}\right)$ [1], [26].

136 Previous studies suggested the removal of possible large137 scale topographic trends (i.e., the bed slope), which causes the 138 spatial basis in the collected spatial data, before calculation 139 of the 2DVS [5]. In this research, the planar detrending was 140 applied to each ALS $6 \mathrm{~m} \times 6 \mathrm{~m}$ subset, and the elevation 141 residuals were used for calculation of the 2DVS.
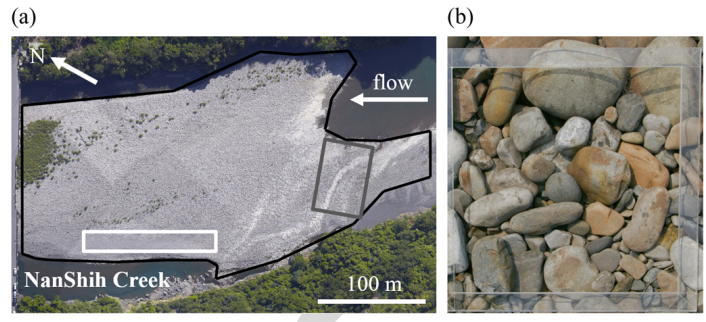

Fig. 1. (a) Georectified orthophoto with a spatial resolution of $5 \mathrm{~cm} \times 5 \mathrm{~cm}$ showing the gravel bar near the confluence of the NanShih Creek and PeiShih Creek, northern Taiwan, with a latitude of $24^{\circ} 54^{\prime} 10^{\prime \prime} \mathrm{N}$ and longitude of $121^{\circ} 33^{\prime} 24^{\prime \prime}$ E. The black polygon shows the extent of exposed gravel bed. The gray rectangle represents a temporally submerged area caused by daily discharge fluctuations. The white rectangle represents an area that is covered by silt and gravel. (b) Image taken from the $50 \mathrm{~cm} \times 50 \mathrm{~cm}$ acrylic frame for photo-sieving.

\section{B. Automatic Determination of Anisotropy Direction by Ellipse Fitting}

The 2DVS expressed as a contour plot can facilitate the 144 analysis of spatial continuity (i.e., spatial autocorrelation) by 145 visualizing the spatial variability along all directions simultane- 146 ously [1], [26]. It is thus suggested that the anisotropy direction 147 can be determined by tracing one of the elliptical contours in 148 the 2DVS [26].

The procedure for determining the PCD is described as fol- 150 lows. First, because the magnitude of the contours of the 2DVS 151 is influenced by the actual semivariances $\hat{\gamma}\left(\mathbf{h}_{x}, \mathbf{h}_{y}\right)$, the semi- 152 variances $\hat{\gamma}\left(\mathbf{h}_{x}, \mathbf{h}_{y}\right)$ in the 2DVS were standardized (divided by 153 the variance of the elevation residuals for each ALS $6 \mathrm{~m} \times 6 \mathrm{~m} 154$ subset), which implies that the contour levels in the 2DVS range 155 theoretically between 0 and just greater than 1 (the maximum 156 theoretical value is equal to the a priori variance not the sample 157 variance). Then, we applied an ellipse-fitting procedure to all 158 elliptical contours of the 2DVS such that the PCD, which rep- 159 resents the direction of greatest spatial continuity (i.e., spatial 160 autocorrelation), is estimated as the direction of the major axis 161 of the fitted ellipse. Since the number of available contour levels 162 in the 2DVS is inherently affected by the spatial autocorrelation 163 property of the subject under investigation (in our case, the ALS 164 point cloud of a exposed gravel bed), this raises difficulties in 165 choosing the contour with a specific contour level for each ALS 166 $6 \mathrm{~m} \times 6 \mathrm{~m}$ subset. As a result, the PCD is determined when the 167 semimajor length of fitted ellipses falls in a given range derived 168 by the grain size characteristic $d_{50}$. We chose the $d_{50}$ value 169 as a physically based guidance in the ellipse-fitting procedure, 170 rather than an arbitrary measurement value, with the hope to 171 maximize the transferability of this procedure to other study 172 areas. The test results for determining the range constraint are 173 shown in section Determination of ALS-derived PCDs.

\section{DATA}

The study area [Fig. 1(a)] is an exposed gravel bed (denoted 176 as the black polygon) near the confluence of the NanShih 177 Creek and PeiShih Creek, northern Taiwan, with latitude and 178 longitude of $24^{\circ} 54^{\prime} 10^{\prime \prime} \mathrm{N}$ and $121^{\circ} 33^{\prime} 24^{\prime \prime} \mathrm{E}$, respectively. The 179 gravel bed was occasionally submerged and migrated by severe 180 floods caused by typhoons that occurred between May and 181 November of each year. It is noted that low discharges would 182 temporarily cause a submerged area, which is denoted by the 183 gray rectangle in Fig. 1(a). 
185 Fig. 1(b) shows one of the 22 image samples, which were 186 taken from the $50 \mathrm{~cm} \times 50 \mathrm{~cm}$ acrylic frame in the exposed 187 gravel bed in Fig. 1(a). We applied the photo-sieving technique 188 developed by Graham et al. [27] to derive the particle size 189 distribution aggregated from the 22 image samples, and the 190 resultant $d_{50}$ is equal to $5.5 \mathrm{~cm}$.

\section{A. ALS}

192 An ALS survey was conducted on May 7, 2009, at the above 193 ground level of $650 \mathrm{~m}$ along the river channel using an Optech 194 ALTM 3070 system onboard a helicopter with nominal eleva195 tion and horizontal accuracies of 15 and $32.5 \mathrm{~cm}$, respectively. 196 The average point cloud density was $247 \mathrm{pts} \cdot \mathrm{m}^{-2}$. Further197 more, aerial photographs were also collected by a medium198 format digital camera, integrated with an Optech ALTM 3070, 199 simultaneously with laser scanning in order to generate georec200 tified orthophotos with a spatial resolution of $5 \mathrm{~cm} \times 5 \mathrm{~cm}$, as 201 shown in Fig. 1(a).

202 For the ALS data of the exposed gravel bed, first, the extreme 203 high points were removed manually. Then, the whole point data 204 were divided into a series of $6 \mathrm{~m} \times 6 \mathrm{~m}$ subsets, each of which 205 was aligned with the longitudinal and transverse directions in 206 the mainstream of NanShih Creek. The mean spacing between 207 the centers of $6 \mathrm{~m} \times 6 \mathrm{~m}$ subsets is $8 \mathrm{~m}$. The specific $6 \mathrm{~m} \times 6 \mathrm{~m}$ 208 subset size was chosen because our previous study [8] demon209 strated that, using this size, reliable anisotropy patterns can 210 be obtained for each subset while maximizing the number of 211 available subsets. Furthermore, in order to avoid the potential 212 bias caused by vegetation (sparse and short Miscanthus) on the 213 gravel bed, we calculated the 2DVSs of ALS $6 \mathrm{~m} \times 6 \mathrm{~m}$ data 214 sets only where the cumulative vegetation area was smaller than $2151 \mathrm{~m}^{2}$ with the help of the 5-cm resolution orthophoto. This leads 216 to 324 subsets available for 2DVS calculation.

217 The ALS data are also used to produce the DEM of the dry 218 surfaces within the study area with a resolution of $1 \mathrm{~m} \times 1 \mathrm{~m}$, 219 where the point clouds belonging to vegetation were removed 220 by visual inspection in Terrscan environment. Due to the in221 frared wavelength of $1064 \mathrm{~nm}$ operated by the ALTM 3070, 222 water absorption prevents ALS measurement for underwater 223 surfaces. The underwater elevations were thus measured using 224 a total station and surveying prism pole in wadable areas, while 225 a shipboard single-beam SONAR was used to survey deeper 226 areas in June 2009. To facilitate the integration of a complete 227 DEM of the study area, all surveying, including ALS, was 228 referenced to TWD97 datum, the national coordinate system 229 of Taiwan. The DEMs of the wet surfaces of a resolution of $2301 \mathrm{~m} \times 1 \mathrm{~m}$ were interpolated from total station and SONAR 231 data. The complete DEM of the study area was created by 232 mosaicking the two DEMs of the dry and wet surfaces, respec233 tively, and was further used for hydrodynamic modeling.

\section{B. Hydrodynamic Modeling}

235 To explore the relation between the ALS-derived PCDs and 236 flow directions, we simulated the depth-averaged 2-D flow 237 fields under high- and low-flow scenarios using a finite-element 238 (FE) hydrodynamic model developed by $\mathrm{Wu}$ et al. [28]. The 239 computational domain, extending $600 \mathrm{~m}$ to the Hsintien Creek 240 and 700 and $500 \mathrm{~m}$ to the NanShih and PeiShih Creeks 241 [Fig. 2(a)], contained 17105 elements and 9000 nodes with a
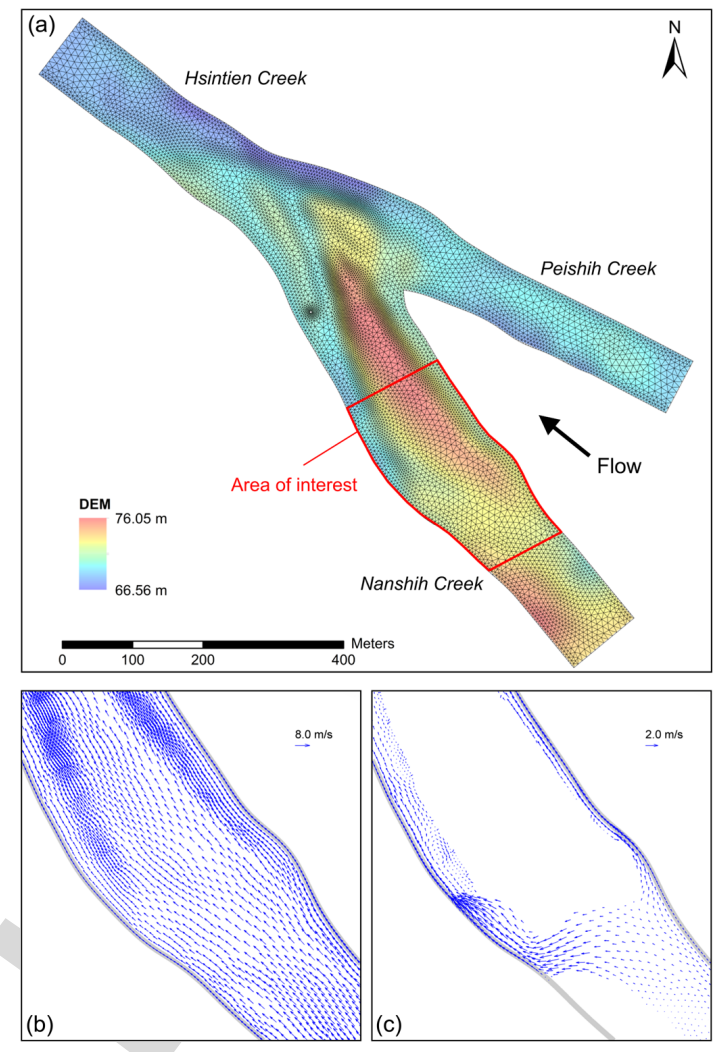

Fig. 2. (a) ALS-derived DEM map and computational mesh of simulation domain, which extends $600 \mathrm{~m}$ to the Hsintien Creek and 700 and $500 \mathrm{~m}$ to the NanShih and PeiShih Creeks, and contains 17105 elements and 9000 nodes with a mean spacing of $4 \mathrm{~m}$; simulated velocity vectors under (b) high-flow and (c) low-flow scenarios, where the regions without velocity data are exposed bars. The scenario simulations exhibit different extents of bar submergence and distinct patterns of 2-D flow field.

mean spacing of $4 \mathrm{~m}$. The ALS-derived DEM was mapped 242 to the FE grids via a triangulated irregular network shown in 243 Fig. 2(a). The model was validated with the observed water lev- 244 els [29]. The calibrated parameter values were then used for the 245 scenario simulations. The upstream boundary conditions (BC) 246 were specified with the flows from the NanShih and PeiShih 247 Creeks, while the downstream BC was specified with the water 248 depth at the Hsintien Creek. For the high-flow scenario, the 249 specified flows (3400 and $1230 \mathrm{~m}^{3} \mathrm{~s}^{-1}$ ) are equivalent to a flood 250 event with seven-year return period; for the low-flow scenario, 251 the specified values (23 and $18 \mathrm{~m}^{3} \mathrm{~s}^{-1}$ ) correspond to flows 252 with a $50 \%$ probability of exceedance. These two scenario 253 simulations exhibited different extents of bar submergence and 254 distinct patterns of 2-D flow field [Fig. 2(b) and (c)]. The 255 simulated velocity vectors at the FE nodes were interpolated 256 to the centers of the $6 \mathrm{~m} \times 6 \mathrm{~m}$ ALS subset, allowing direct 257 comparisons of the ALS-derived PCDs and flow directions. 258

\section{REsults AND Discussion}

A. Anisotropy Property of $2 \mathrm{DVSS}$

The 2DVSs of the 324 ALS $6 \mathrm{~m} \times 6 \mathrm{~m}$ subsets were com- 261 puted using the R software, and the contour map of the 2DVS 262 was generated using a purpose-written MATLAB program. 263 Based on internal testing, the lag distance of the 2DVS and the 264 contour level interval in the contour plot were set to $15 \mathrm{~cm}$ and 265 0.05 , respectively, to best reveal anisotropic structures. 
(a)

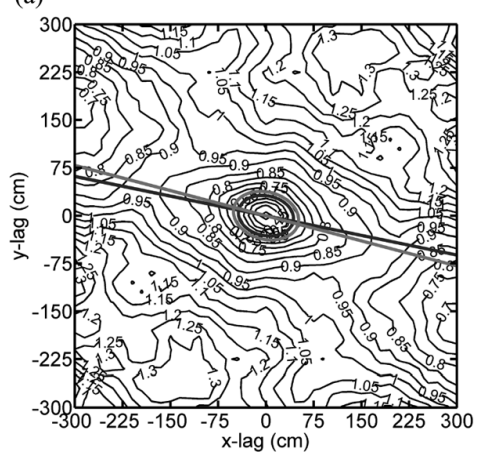

(b)

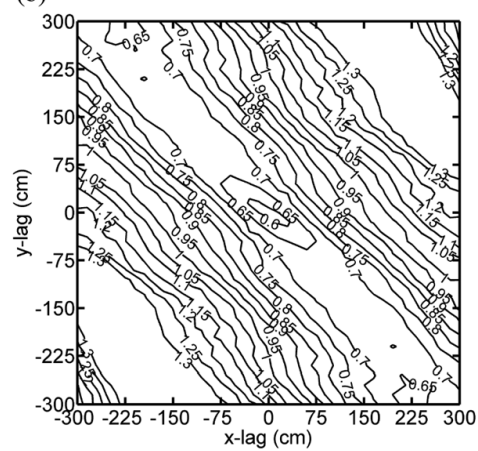

(c)

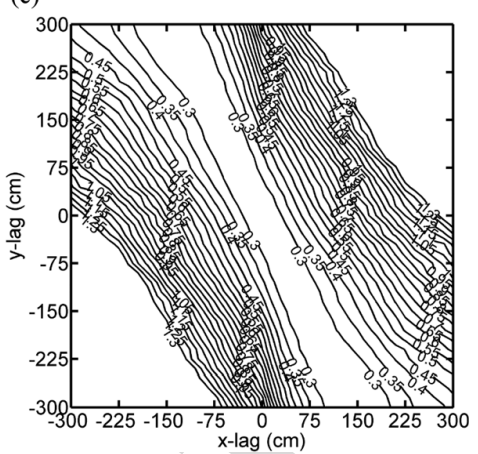

Fig. 3. (a) Contours of the 2DVS reveal a clear anisotropic structure. The ellipse-fitting procedure was applied to the black and gray contour, respectively, in order to determine the PCDs. The black and gray lines are the PCDs determined from the fitted ellipse with the semimajor axis lengths equal to $8.0 d_{50}$ and $9.5 d_{50}$, respectively. The contours of the 2DVS in (b) and (c) show a clear anisotropic structure, but there exist only parallel contours in (c), which prevents application of the ellipse-fitting procedure to obtain the PCD.

267 Most of the 2DVSs of the ALS $6 \mathrm{~m} \times 6 \mathrm{~m}$ subsets revealed 268 a clear anisotropic structure similar to the contours shown 269 in Fig. 3(a). It is thus appropriate to apply the ellipse-fitting 270 procedure to a specific contour to determine the PCD. While a 271 small number of subsets show fewer [Fig. 3(b)] or no [Fig. 3(c)] 272 elliptical contours in their 2DVS, the anisotropic structure is 273 still prominent. Based on visual inspection, the 2DVSs similar 274 to Fig. 3(b) and (c) appeared to be in the area covered by silt and 275 gravel, which is highlighted by the white rectangle in Fig. 1(a). 276 Due to the requirement of ellipse fitting, the ALS-derived PCDs 277 are only available for those 2DVSs similar to Fig. 3(a) and (b).

\section{B. Determination of ALS-Derived PCDs}

279 To mitigate the influence of the jagged appearance of the 280 elliptical contours with small lag distances [c.f., Fig. 3(a)] on 281 the PCD estimation, we applied the ellipse-fitting procedure 282 only to those contour lines including more than 20 cells in the 283 2DVS, which implies that the semimajor axis length of the fitted 284 ellipse should be larger than $7 d_{50}$ in our study area.

285 When there are more than two candidate contour lines that 286 fall in a range of multiple times of $d_{50}$, we select the PCD 287 with the smallest semimajor axis length. As shown in our data, 288 the difference between different PCDs is insignificant. Fig. 3(a) 289 shows an example for the determination of the PCD with the 290 semimajor axis length constraint being 7-10 $d_{50}$, and two 291 candidate contours with their semimajor axis lengths of $8.0 d_{50}$ 292 [black line in Fig. 3(a)] and $9.5 d_{50}$ [gray line in Fig. 3(a)] 293 were found, where the former one would be reported. The angle 294 difference between these two PCDs is as small as $3^{\circ}$.

295 To further examine the insignificance of PCD bias caused by 296 the choice of semimajor axis length constraint in the ellipse fit297 ting, we generated three sets of ALS-derived PCDs determined 298 from the semimajor axis length within three ranges, i.e., $7-10 d_{50}$, 299 9-12 $d_{50}$, and 11-14 $d_{50}$, and compared these PCD results with 300 the simulated high- and low-flow directions. The choice of these 301 constraint ranges was made in order to maximize of chance of 302 having at least one available contour for each constraint.

\section{C. Comparison of ALS-Derived PCDs and Simulated} 304 Flow Directions

305 The angle differences of the ALS-derived PCDs and simu306 lated flow directions were calculated. The positive angle dif-
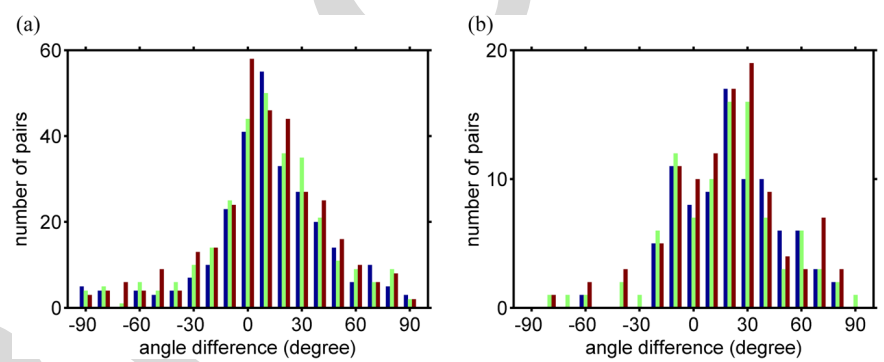

Fig. 4. Histograms of the angle differences between the three sets of ALSderived PCDs and simulated flow directions at (a) high and (b) low flow. The red, green, and blue bins represent the histograms of the angle differences calculated from the three sets of ALS-derived PCDs determined by the semimajor axis length constraints, which are 7-10 $d_{50}, 9-12 d_{50}$, and $11-14 d_{50}$, respectively.

ferences denote that the ALS-derived PCD lies to the left of 307 the simulated flow directions when facing downstream; the 308 negative angle differences denote that the ALS-derived PCD 309 lies to the right of the simulated flow directions. 310

The histograms of the angle differences for high and low 311 flow are shown in Fig. 4(a) and (b), respectively. The red, 312 green, and blue bins in Fig. 4 represent the histograms of the 313 angle differences calculated from the three sets of ALS-derived 314 PCDs determined by the semimajor axis length constraints 315 being 7-10 $d_{50}, 9-12 d_{50}$, and 11-14 $d_{50}$, respectively. For the 316 high flow, the total numbers of comparison pairs are 324, 299, 317 and 275 when the semimajor axis constraints are 7-10 $d_{50}, 318$ 9-12 $d_{50}$, and 11-14 $d_{50}$, respectively; for the low flow, the total 319 numbers of comparison pairs become 107, 96, and 89 when 320 the semimajor axis constraints are 7-10 $d_{50}, 9-12 d_{50}$, and 321 $11-14 d_{50}$, respectively. Because the submerged area is much 322 smaller for low-flow condition [c.f., Fig. 2(c)], the number of 323 comparison pairs for low flow was much less than that for high 324 flow. Furthermore, we noted that the number of available ALS- 325 derived PCDs decreased with the increase of the semimajor 326 axis length constraint. Because the semivariances of 2DVS are 327 expected to increase slowly at large lag distances [1], [26], 328 the larger spacing of contours in the 2DVS leads to fewer 329 contours available for ellipse fitting. As observed in Fig. 3(a), 330 the elliptical contours starting from 0.5 to 0.9 become sparse. It 331 is also noted that the contours became fragmented, and it was 332 not easy to find ellipse shape [as shown in the upper left and 333 lower right corner in Fig. 3(a)] when the data are not able to 334 reveal such long range spatial correlation in the 2DVS. 
(a)

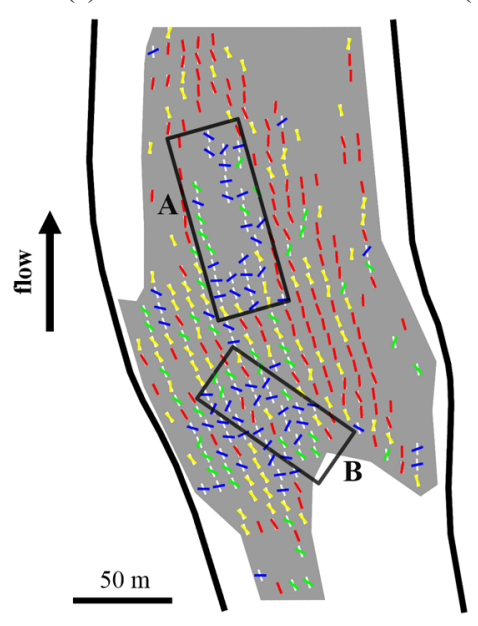

(b)

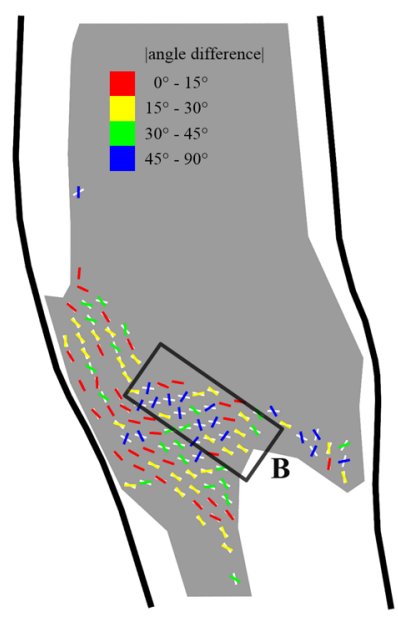

Fig. 5. Comparison of the ALS-derived PCDs and simulated flow directions at (a) high and (b) low flow. The gray polygon is the extent of the exposed gravel bed. The white segments represent the simulated flow directions. The red, yellow, green, and blue segments denote the absolute values of angle difference of $0^{\circ}-15^{\circ}, 15^{\circ}-30^{\circ}, 30^{\circ}-45^{\circ}$, and $45^{\circ}-90^{\circ}$, respectively, of the ALS-derived PCDs with respect to simulated flow directions. Rectangle A denotes the area with notable discrepancies of ALS-derived PCDs and highflow direction. Rectangle B denotes the area where the ALS-derived PCDs have better agreement with low-flow direction than high-flow direction.

336 As observed in Fig. 4, the distributions of the angle differ337 ences with three different semimajor axis constraints for high 338 and low flow are, respectively, similar. To further demonstrate 339 the similarity between each distribution of angle difference, 340 for high and low flow, respectively, we applied the nonpara341 metric Kruskal-Wallis test, implemented in $\mathrm{R}$ software. The 342 null hypothesis for the Kruskal-Wallis test is that the three 343 sets of angle differences come from the same distribution. The 344 resultant $p$-values for the Kruskal-Wallis test are 0.89 and 0.83 345 for high and low flow, respectively, both of which failed to reject 346 the null hypothesis at the significant level of 0.05 . This implies 347 that the angle differences calculated from the three sets of 348 ALS-derived PCDs and simulated flow directions do not reveal 349 statistically significant differences. It is thus suggested that the 350 ALS-derived PCDs derived from any elliptical contour of the 351 2DVS should exhibit similar orientation when the contours 352 of the 2DVS reveal the clear anisotropic structure. The ALS353 derived PCDs determined with the semimajor axis length con354 straint of $7-10 d_{50}$ are discussed as it gave the largest number 355 of comparison pairs.

356 Fig. 5(a) and (b) demonstrates the comparison of ALS357 derived PCDs and simulated high- and low-flow directions, 358 respectively. The gray polygon in Fig. 5 shows the extent 359 of exposed gravel bed [also shown as the black polygon in 360 Fig. 1(a)]. The white segments in Fig. 5 represent the simulated 361 flow directions. We observed that the simulated flow directions 362 for high flow are primarily parallel to the main stream direc363 tion in Fig. 5(a). Moreover, the simulated low flow primarily 364 flows through the temporarily submerged area in Fig. 5(b) 365 [c.f., the gray rectangle in Fig. 1(a)]. The red, yellow, green, 366 and blue segments in Fig. 5 denote the absolute values of 367 angle difference of $0^{\circ}-15^{\circ}, 15^{\circ}-30^{\circ}, 30^{\circ}-45^{\circ}$, and $45^{\circ}-90^{\circ}$, 368 respectively, of the ALS-derived PCDs with respect to simu369 lated flow directions.

We noted a good agreement between the ALS-derived PCDs 370 and simulated high flow in the right portion of the exposed 371 gravel bar [Fig. 5(a)], where the white segments become invis- 372 ible due to the insignificant angle difference between the ALS- 373 derived PCDs and simulated high flow. This implies a potential 374 for inferring high-flow direction from ALS-derived PCD for 375 this area. However, an area with notable discrepancies of the 376 ALS-derived PCDs and high-flow direction is also presented 377 [denoted as rectangle A in Fig. 5(a)]. For the temporarily 378 submerged gravel bed area, we observed that the ALS-derived 379 PCDs showed better agreement with the simulated low-flow 380 direction than the high-flow direction [where a larger number 381 of red and yellow segments are found in Fig. 5(b)], expect for 382 the rectangle $\mathrm{B}$ area.

Furthermore, Fig. 4 reveals that the angle differences at high 384 flow exhibit a peak close to $0^{\circ}$, while at low flow, the peak is 385 close to $30^{\circ}$, which suggests that the PCDs of bed surface struc- 386 ture are, overall, better correlated to the high flow. However, for 387 the topographically low spots (e.g., rectangle B in Fig. 5), the 388 low flow might have left a signature on the bed surface during 389 the recession of flood, where the PCDs are better correlated 390 to the low flow. From the aforementioned results, we demon- 391 strated that the ALS-derived PCDs correspond to the flow 392 directions at different flow rates.

393

It is noted that the typhoon-induced torrents were 3-D turbu- 394 lent flows, typically characterized by fluctuating velocities with 395 their magnitudes and directions changing with time and depth 396 [30]. However, the 2-D hydrodynamic simulation performed 397 herein was based on steady depth-averaged flood flows; thus, 398 the discrepancies between the PCDs of bed surface structure 399 and the computed flow directions may be attributable in part to 400 these unresolved spatial variations.

401

\section{Conclusion}

In summary, we have explored the relationship of the aniso- 403 tropy direction of exposed gravel bed (i.e., the ALS-derived 404 PCDs) and simulated flow directions. We have determined the 405 PCDs from the 2DVSs by applying an ellipse-fitting procedure 406 with consideration given to the grain size characteristic $d_{50} .407$ The angle differences between the ALS-derived PCDs and sim- 408 ulated flow directions were calculated, and the Kruskal-Wallis 409 test was performed on the angle differences. The results suggest 410 that the ALS-derived PCDs estimated from any elliptical con- 411 tour of the 2DVS should exhibit similar orientation when the 412 contours of the 2DVS reveal a clear anisotropic structure. Fur- 413 thermore, the comparison of the ALS-derived PCDs and sim- 414 ulated flow directions shows good agreement, which suggests 415 that ALS-derived PCDs could be used to infer flow direction at 416 different flow rates.

417

What is remarkable here is that the process for determining 418 the PCD in the 2DVS is largely automatic and is scalable. Here, 419 we applied the technique to 324 ALS $6 \mathrm{~m} \times 6 \mathrm{~m}$ subsets, but 420 potentially, this is expandable and scalable to the whole ALS 421 scenes where the river can be adequately demarcated. Thus, this 422 letter points to the potential of determining flow direction across 423 large areas, at both high and low flow, without the need for 424 in situ measurement or simulation modeling. Future research 425 should demonstrate this ability across a range of different flow 426 conditions and for a wider range of gravel bed surfaces. 


\section{REFERENCES}

1] P. Goovaerts, Geostatistics for Natural Resources Evaluation. London, U.K.: Oxford Univ. Press, 1997.

[2] R. Mott, M. Schirmer, and M. Lehning, "Scaling properties of wind and snow depth distribution in an alpine catchment," J. Geophys. Res. Atmos., vol. 116, no. D6, Mar. 2011, Art. no. D06106, doi: 10.1029/ 2010JD014886.

[3] J. Aberle and V. Nikora, "Statistical properties of armored gravel bed surfaces," Water Resour. Res., vol. 42, no. 11, Nov. 2006, Art. no. W11414, doi: 10.1029/2005WR004674.

4] J. B. Butler, S. N. Lane, and J. H. Chandler, "Characterization of the structure of river-bed gravels using 2D fractal analysis," Math. Geol., vol. 33, no. 3, pp. 301-330, Apr. 2001.

[5] R. Hodge, J. Brasington, and K. Richards, "Analysing laser-scanned digital terrain models of gravel bed surfaces: Linking morphology to sediment transport processes and hydraulics," Sedimentology, vol. 56, no. 7, pp. 2024-2043, May 2009.

6] J. Qin, D. Zhong, G. Wangm, and S. L. Ng, "Influence of particle shape on surface roughness: Dissimilar morphological structures formed by man-made and natural gravels," Geomorphology, vol. 190, pp. 16-26, May 2013.

7] P. E. Carbonneau, S. N. Lane, and N. E. Bergeron, "Cost-effective non-metric close-range digital photogrammetry and its application to a study of coarse gravel river beds," Int. J. Remote Sens., vol. 24, no. 14, pp. 2837-2854, Jul. 2003

8] G.-H. Huang and C.-K. Wang, "Multi-scale geostatistical estimation of gravel-bed roughness from terrestrial and airborne laser scanning," IEEE Geosci. Remote Sens. Lett., vol. 9, no. 6, pp 1084-1088, Nov. 2012.

[9] P. K. Kitanidis, Introduction to Geostatistics Applications in Hydrogeology. Cambridge, U.K.: Cambridge Univ. Press, 1997.

0] J. Schlee, "Fluvial gravel fabric," J. Sedimentary Petrol., vol. 27, no. 2, pp. 162-176, 1957.

11] D. J. Douglas, "The structure of sedimentary deposits of braided rivers," Sedimentology, vol. 1, no. 3, pp. 167-190, Sep. 1962.

C. E. Johansson, "Orientation of pebbles in running water: A laboratory study," Geogr. Ann. A, vol. 45, no. 2/3, pp. 85-112, 1963.

13] G. Kelling and P. F. Williams, "Flume studies of the reorientation of pebbles and shells," J. Geol., vol. 75, no. 3, pp. 243-267, May 1967.

B. R. Rust, "Pebble orientation in fluvial sediments," J. Sedimentary Petrol., vol. 42, no. 2, pp. 384-388, Jun. 1972.

15] M. E. Kauffman and D. F. Ritter, "Cobble imbrication as a sensitive indicator of subtle local changes in river flow direction," Geology, vol. 9 , no. 7, pp. 299-302, Jul. 1981.
[16] R. P. Millane, M. I. Weir, and G. M. Smart, "Automated analysis of im- 472 brication and flow direction in alluvial sediments using laser-scan data," 473 J. Sedimentary Res., vol. 76, no. 8, pp. 1049-1055, Aug. 2006.

[17] J. B. Laronne and M. A. Carson, "Interrelationships between bed mor- 475 phology and bed-material transport for a small, gravel-bed channel," 476 Sedimentology, vol. 23, no. 1, pp. 67-85, Feb. 1976. 477

[18] S. Bertin and H. Friedrich, "Field application of close-range digital pho- 478 togrammetry (CRDP) for grain-scale fluvial morphology studies," Earth 479 Surf. Process. Landforms, to be published, doi: 10.1002/esp.3906. 480

[19] G. Smart, J. Aberle, M. Duncan, and J. Walsh, "Measurement and analysis 481 of alluvial bed roughness," J. Hydraulic Res., vol. 42, no. 3, pp. 227-237, 482 2004

[20] L. Mao, J. R. Cooper, and L. E. Frostick, "Grain size and topographical 484 differences between static and mobile armour layers," Earth Surf. Process. 485 Landforms, vol. 36, no. 10, pp. 1321-1334, Aug. 2011.

[21] R. M. Westaway, S. N. Lane, and D. M. Hicks, "Remote survey of large- 487 scale braided, gravel-bed rivers using digital photogrammetry and image 488 analysis," Int. J. Remote Sens., vol. 24, no. 4, pp. 795-815, 2003.

[22] A. S. Woodget, P. E. Carbonneau, F. Visser, and I. P. Maddock, "Quantify- 490 ing submerged fluvial topography using hyperspatial resolution UAS im- 491 agery and structure from motion photogrammetry," Earth Surf. Process. 492 Landforms, vol. 40, no. 1, pp. 47-64, Jan. 2015.

[23] A. D. Tamminga, B. C. Eaton, and C. H. Hugenholtz, "UAS-based remote 494 sensing of fluvial change following an extreme flood event," Earth Surf. 495 Process. Landforms, vol. 40, no. 11, pp. 1464-1476, Sep. 2015.

[24] J. Hohenthal, P. Alho, J. Hyyppä, and H. Hyyppä, "Laser scanning appli- 497 cations in fluvial studies," Progr. Phys. Geogr., vol. 35, no. 6, pp. 782-809, 498 Dec. 2011.

[25] "Titan Multispectral Lidar System Datasheet," Teledyne Optech Inc., 500 Kiln, MS, USA, Accessed Mar. 15, 2016. [Online]. Available: http:// 501 www.teledyneoptech.com/wp-content/uploads/Titan-Specsheet-150515- 502 WEB.pdf

[26] E. H. Isaaks and R. M. Srivastava, Applied Geostatistics. New York, NY, 504 USA: Oxford Univ. Press, 1989.

[27] D. J. Graham, S. mated grain sizing of river gravels," Water Resour. Res., vol. 41, Jul. 2005, 507 Art. no. W07020, doi: 10.1029/2004WR003868.

[28] F.-C. Wu, Y.-C. Shao, and Y.-C. Chen, "Quantifying the forcing effect of 509 channel width variations on free bars: Morphodynamic modeling based 510 on characteristic dissipative Galerkin scheme," J. Geophys. Res., vol. 116, 511 Sep. 2011, Art. no. F03023, doi: 10.1029/2010JF001941.

[29] "Planning Report for Training of Upstream," Water Resour. Agency 513 (WRA), New Taipei, Taiwan, 2009.

[30] J. S. Bridge, Rivers and Floodplains: Forms, Processes, and Sedimentary 515 Record. Hoboken, NJ, USA: Wiley-Blackwell, 2003. 


\section{AUTHOR QUERIES}

\section{AUTHOR PLEASE ANSWER ALL QUERIES}

The paper exceeds the maximum allowable number of pages. Please shorten the paper to fit into five pages.

Please be aware that authors are required to pay overlength page charges ( $\$ 200$ per page) if the paper is longer than 3 pages. If you cannot pay any or all of these charges please let us know.

This pdf contains 2 proofs. The first half is the version that will appear on Xplore. The second half is the version that will appear in print. If you have any figures to print in color, they will be in color in both proofs.

The "Open Access" option for your paper expires when the paper is published on Xplore in an issue with page numbers. Papers in "Early Access" may be changed to "Open Access."

AQ1 = Please check if there is a need to change "expect" to "except." AQ2 = Please provide publication update in Ref. [18].

END OF ALL QUERIES 


\title{
Anisotropy Characteristics of Exposed Gravel Beds Revealed in High-Point-Density Airborne Laser Scanning Data
}

\author{
Guo-Hao Huang, Chi-Kuei Wang, Fu-Chun Wu, and Peter M. Atkinson
}

\begin{abstract}
5 Abstract-The aim of this study was to examine the relation6 ship between the anisotropy direction of exposed gravel bed and 7 flow direction. Previous studies have shown that the anisotropy 8 direction of a gravel bed surface can be visually determined in the 9 elliptical contours of 2-D variogram surface (2DVS). In this letter, 10 airborne laser scanning (ALS) point clouds were acquired at a 11 gravel bed, and the whole data set was divided into a series of $126 \mathbf{m} \times 6 \mathrm{~m}$ subsets. To estimate the direction of anisotropy, we 13 proposed an ellipse-fitting-based automatic procedure with con14 sideration given to the grain size characteristic $d_{50}$ to estimate the 15 primary axis of anisotropy [hereafter referred to as the primary 16 continuity direction (PCD)] in the 2DVS. The ALS-derived PCDs 17 were compared to the flow directions (for both high and low 18 flow) derived from hydrodynamic model simulation. Comparison 19 of ALS-derived PCDs and simulated flow directions suggested that 20 ALS-derived PCDs could be used to infer flow direction at differ21 ent flow rates. Furthermore, we found that the ALS-derived PCDs 22 estimated from any elliptical contour of the 2DVS exhibited a simi23 lar orientation when the contours of the 2DVS reveal the clear an24 isotropic structure, demonstrating the robustness of the technique.
\end{abstract}

25 Index Terms-Airborne laser scanning (ALS), flow direction, 26 spatial continuity, 2-D variogram surface (2DVS).

\section{INTRODUCTION}

28

${ }_{30}^{2} \mathbf{T}$ HE geostatistical variogram function has been recognized as an important tool for detecting spatial anisotropy in 31 different variables, such as air pollution [1], snow depth [2], and 32 exposed gravel bed structures [3]-[8]. The anisotropy indicates 33 that the spatial correlation pattern changes with orientation, 34 and it can be represented by the elliptical contours in a 2-D 35 variogram surface (2DVS).

36 Many studies have shown that the visually determined 37 anisotropy direction of a 2DVS can be associated with different 38 mechanisms, such as wind for air pollution and snow depth 39 structures [1], [2] and hydrodynamic dispersion (i.e., flow

Manuscript received November 8, 2015; revised March 16, 2016 and April 11, 2016; accepted April 27, 2016.

G.-H. Huang and C.-K. Wang are with the Department of Geomatics, National Cheng Kung University, Tainan 70101, Taiwan (e-mail: chikuei@ mail.ncku.edu.tw).

F.-C. Wu is with the Department of Bioenvironmental Systems Engineering, National Taiwan University, Taipei 10617, Taiwan.

P. M. Atkinson is with the Department of Geography and Environment, University of Southampton, SO17 1BJ Southampton, U.K., with the Faculty of Science and Technology, Lancaster University, Lancaster LA1 4YW, U.K., with the Faculty of Geosciences, University of Utrecht, 3584 Utrecht, The Netherlands, and also with the School of Geography, Archaeology and Palaeoecology, Queen's University, Belfast BT7 1NN, U.K.

Color versions of one or more of the figures in this paper are available online at http://ieeexplore.ieee.org.

Digital Object Identifier 10.1109/LGRS.2016.2562061 movement) for homogeneous porous media [9]. In the last two 40 decades, substantial studies have investigated the anisotropy 41 directions derived from a 2DVS in the exposed gravel beds and 42 suggested that the anisotropy directions exhibited in the gravel 43 bed surfaces reflect the dominant grain orientation [3]-[6]. 44 Various studies have examined the relationship between gravel 45 orientation and flow direction [10]-[16]. For lower flows, larger 46 pebbles, and lower pebble concentrations, elongated pebbles 47 are transported by rolling and are deposited with their major 48 axes normal to the flow direction. For higher flows, smaller 49 pebbles, and higher pebble concentrations, the pebbles skip 50 along the bed and tend to be deposited with their major axis 51 parallel to the flow [16]. It has been reported that particle 52 imbrication would occur naturally in a direction parallel to 53 the flow [5], [16], [17]. Particle imbrication covering a range 54 of directions might indicate that flow direction changed over 55 the duration of the last competent event (e.g., varied with 56 flow depth) or that different flows (with different directions) 57 imbricated particles in different ways over time [16]. It has 58 also been reported that the anisotropy directions failed at being 59 conclusive on the surface-forming flow direction [5], [18]. The 60 latter is notoriously difficult to determine accurately from in situ 61 visual observations [19].

The determination of flow direction is essential to trace the 63 water paths and sediment transportation. For coarse bed materi- 64 als, rolling/sliding and saltation are the most possible modes of 65 sediment transport, with rolling/sliding dominated by coarser 66 pebbles and saltation dominated by finer gravel. Alignment 67 of bed particles transverse to the flow can be associated with 68 transport mode by rolling and sliding [17], while bed structure 69 longitudinal to the flow can be attributed to deposition of 70 saltating particles after contact with the upstream front of stable 71 grain and particle imbrications [4], [5], [20]. It is thus of interest 72 to explore the relationship between the anisotropy of gravel 73 bed surfaces and flow direction across large areas. However, 74 comparison of anisotropy direction determined visually from 75 a 2DVS, extracted for laboratory and field gravel surfaces, to 76 flow direction determined from subjective observation [3]-[6] 77 revealed no common consensus about the relationship between 78 anisotropy direction and flow movement in exposed gravel 79 beds. This is possibly due to the limited numbers of data and 80 the small spatial extents available to earlier researchers.

Advances in remote sensing have facilitated the measurement 82 of gravel bed surfaces in a spatially extensive and cost-effective 83 way based on the airborne approach, including airborne laser 84 scanning (ALS), aerial photogrammetry, and unmanned aerial 85 systems (UASs) [8], [21]-[23]. Huang and Wang [8] have 86 indicated that a detailed description of gravel bed surfaces is 87 
88 a prerequisite for visualizing the obvious anisotropy pattern in 89 the 2DVS of gravel bed surfaces. Recent progress on combining 90 UAS and structure-from-motion photogrammetry has gained 91 attention for measuring submerged and dry gravel beds, and 92 it has been shown that a digital elevation model (DEM) with 93 a spatial resolution of a few centimeters can be achieved [22], 94 [23]. However, the UAS has to be operated at a low altitude 95 (i.e., lower than $100 \mathrm{~m}$ ) for such a purpose, and this would be 96 challenging when performing UAS surveys in river valleys. The 97 ALS, which incorporates laser ranging, inertial measurement 98 unit, and Global Positioning System technologies, has shown 99 potential for mapping the surface elevation of a large area [24]. 100 Moreover, the pulse repetition frequencies of the commercial 101 ALS systems have increased from $70 \mathrm{kHz}$ in 2003 (as for the 102 ALS used in this study) to $900 \mathrm{kHz}$ in 2014 [25], which shows 103 that the ALS is now economically favorable for capturing 104 gravel bed surfaces with high-density ALS point clouds.

105 In this research, we examined the anisotropy characteristics 106 of a very high-point-density ALS data of an exposed gravel 107 bed by comparing its anisotropy direction with simulated flow 108 directions under high- and low-flow scenarios based on fixed109 bed hydrodynamic modeling. To better reveal the variation of 110 the anisotropy characteristic within the river channel, the whole 111 ALS data set was divided into a series of $6 \mathrm{~m} \times 6 \mathrm{~m}$ subsets, 112 which results in 324 subsets of ALS point data. In order to 113 consistently derive the anisotropy direction for each $6 \mathrm{~m} \times 6 \mathrm{~m}$ 114 subset, we devised an ellipse-fitting-based automatic procedure 115 with the consideration of the grain size characteristic $d_{50}$, which 116 is the median of particle size distribution, to determine the 117 primary axis of anisotropy [hereafter, referred to as the primary 118 continuity direction (PCD)] in the 2DVS.

\section{9}

\section{METHOD}

\section{A. 2DVS}

121 The variogram has been used widely to quantify the spatial 122 variability in gravel bed surfaces [4], [5], [8]. The empirical 123 variogram, which is half the mean squared difference between 124 pairs of data points separated by the lag vector $\mathbf{h}$, can be 125 expressed as

$$
\hat{\gamma}(\mathbf{h})=\frac{1}{2 N(\mathbf{h})} \sum_{i=1}^{N(\mathbf{h})}\left[z\left(\mathbf{x}_{i}\right)-z\left(\mathbf{x}_{i}+\mathbf{h}\right)\right]^{2}
$$

126 where $\hat{\gamma}(\mathbf{h})$ is the semivariance, the lag (distance and direction) 127 vector $\mathbf{h}$ is the separation between two data points, $N(\mathbf{h})$ is the 128 number of point pairs separated by lag $\mathbf{h}$, and $z\left(\mathbf{x}_{i}\right)$ is the bed 129 elevation at the location $\mathbf{x}_{i}$.

130 The empirical variogram is a function that relates semivari131 ance $\hat{\gamma}(\mathbf{h})$ to lag $\mathbf{h}$ and is usually expressed as a set of 1-D plots, 132 where different plots represent different directions. An alterna133 tive is to plot all directions together as a 2DVS, i.e., a raster map 134 of semivariance values $\hat{\gamma}\left(\mathbf{h}_{x}, \mathbf{h}_{y}\right)$ representing the empirical 135 variogram for all available lag vectors $\mathbf{h}=\left(\mathbf{h}_{x}, \mathbf{h}_{y}\right)$ [1], [26].

136 Previous studies suggested the removal of possible large137 scale topographic trends (i.e., the bed slope), which causes the 138 spatial basis in the collected spatial data, before calculation 139 of the 2DVS [5]. In this research, the planar detrending was 140 applied to each ALS $6 \mathrm{~m} \times 6 \mathrm{~m}$ subset, and the elevation 141 residuals were used for calculation of the 2DVS.
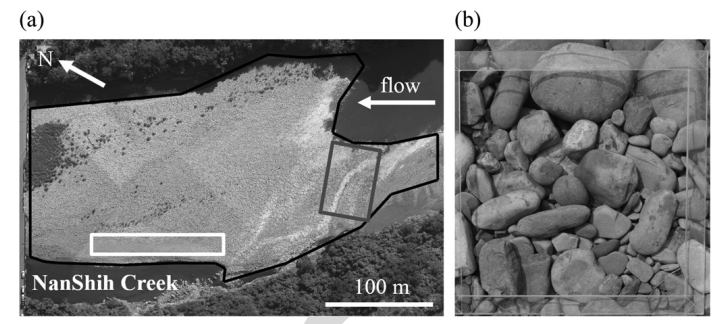

Fig. 1. (a) Georectified orthophoto with a spatial resolution of $5 \mathrm{~cm} \times 5 \mathrm{~cm}$ showing the gravel bar near the confluence of the NanShih Creek and PeiShih Creek, northern Taiwan, with a latitude of $24^{\circ} 54^{\prime} 10^{\prime \prime} \mathrm{N}$ and longitude of $121^{\circ} 33^{\prime} 24^{\prime \prime}$ E. The black polygon shows the extent of exposed gravel bed. The gray rectangle represents a temporally submerged area caused by daily discharge fluctuations. The white rectangle represents an area that is covered by silt and gravel. (b) Image taken from the $50 \mathrm{~cm} \times 50 \mathrm{~cm}$ acrylic frame for photo-sieving.

\section{B. Automatic Determination of Anisotropy Direction by Ellipse Fitting}

The 2DVS expressed as a contour plot can facilitate the 144 analysis of spatial continuity (i.e., spatial autocorrelation) by 145 visualizing the spatial variability along all directions simultane- 146 ously [1], [26]. It is thus suggested that the anisotropy direction 147 can be determined by tracing one of the elliptical contours in 148 the 2DVS [26].

The procedure for determining the PCD is described as fol- 150 lows. First, because the magnitude of the contours of the 2DVS 151 is influenced by the actual semivariances $\hat{\gamma}\left(\mathbf{h}_{x}, \mathbf{h}_{y}\right)$, the semi- 152 variances $\hat{\gamma}\left(\mathbf{h}_{x}, \mathbf{h}_{y}\right)$ in the 2DVS were standardized (divided by 153 the variance of the elevation residuals for each ALS $6 \mathrm{~m} \times 6 \mathrm{~m} 154$ subset), which implies that the contour levels in the 2DVS range 155 theoretically between 0 and just greater than 1 (the maximum 156 theoretical value is equal to the a priori variance not the sample 157 variance). Then, we applied an ellipse-fitting procedure to all 158 elliptical contours of the 2DVS such that the PCD, which rep- 159 resents the direction of greatest spatial continuity (i.e., spatial 160 autocorrelation), is estimated as the direction of the major axis 161 of the fitted ellipse. Since the number of available contour levels 162 in the 2DVS is inherently affected by the spatial autocorrelation 163 property of the subject under investigation (in our case, the ALS 164 point cloud of a exposed gravel bed), this raises difficulties in 165 choosing the contour with a specific contour level for each ALS 166 $6 \mathrm{~m} \times 6 \mathrm{~m}$ subset. As a result, the PCD is determined when the 167 semimajor length of fitted ellipses falls in a given range derived 168 by the grain size characteristic $d_{50}$. We chose the $d_{50}$ value 169 as a physically based guidance in the ellipse-fitting procedure, 170 rather than an arbitrary measurement value, with the hope to 171 maximize the transferability of this procedure to other study 172 areas. The test results for determining the range constraint are 173 shown in section Determination of ALS-derived PCDs.

\section{DATA}

The study area [Fig. 1(a)] is an exposed gravel bed (denoted 176 as the black polygon) near the confluence of the NanShih 177 Creek and PeiShih Creek, northern Taiwan, with latitude and 178 longitude of $24^{\circ} 54^{\prime} 10^{\prime \prime} \mathrm{N}$ and $121^{\circ} 33^{\prime} 24^{\prime \prime}$ E, respectively. The 179 gravel bed was occasionally submerged and migrated by severe 180 floods caused by typhoons that occurred between May and 181 November of each year. It is noted that low discharges would 182 temporarily cause a submerged area, which is denoted by the 183 gray rectangle in Fig. 1(a). 
185 Fig. 1(b) shows one of the 22 image samples, which were 186 taken from the $50 \mathrm{~cm} \times 50 \mathrm{~cm}$ acrylic frame in the exposed 187 gravel bed in Fig. 1(a). We applied the photo-sieving technique 188 developed by Graham et al. [27] to derive the particle size 189 distribution aggregated from the 22 image samples, and the 190 resultant $d_{50}$ is equal to $5.5 \mathrm{~cm}$.

\section{A. ALS}

192 An ALS survey was conducted on May 7, 2009, at the above 193 ground level of $650 \mathrm{~m}$ along the river channel using an Optech 194 ALTM 3070 system onboard a helicopter with nominal eleva195 tion and horizontal accuracies of 15 and $32.5 \mathrm{~cm}$, respectively. 196 The average point cloud density was $247 \mathrm{pts} \cdot \mathrm{m}^{-2}$. Further197 more, aerial photographs were also collected by a medium198 format digital camera, integrated with an Optech ALTM 3070, 199 simultaneously with laser scanning in order to generate georec200 tified orthophotos with a spatial resolution of $5 \mathrm{~cm} \times 5 \mathrm{~cm}$, as 201 shown in Fig. 1(a).

202 For the ALS data of the exposed gravel bed, first, the extreme 203 high points were removed manually. Then, the whole point data 204 were divided into a series of $6 \mathrm{~m} \times 6 \mathrm{~m}$ subsets, each of which 205 was aligned with the longitudinal and transverse directions in 206 the mainstream of NanShih Creek. The mean spacing between 207 the centers of $6 \mathrm{~m} \times 6 \mathrm{~m}$ subsets is $8 \mathrm{~m}$. The specific $6 \mathrm{~m} \times 6 \mathrm{~m}$ 208 subset size was chosen because our previous study [8] demon209 strated that, using this size, reliable anisotropy patterns can 210 be obtained for each subset while maximizing the number of 211 available subsets. Furthermore, in order to avoid the potential 212 bias caused by vegetation (sparse and short Miscanthus) on the 213 gravel bed, we calculated the 2DVSs of ALS $6 \mathrm{~m} \times 6 \mathrm{~m}$ data 214 sets only where the cumulative vegetation area was smaller than $2151 \mathrm{~m}^{2}$ with the help of the 5 -cm resolution orthophoto. This leads 216 to 324 subsets available for 2DVS calculation.

217 The ALS data are also used to produce the DEM of the dry 218 surfaces within the study area with a resolution of $1 \mathrm{~m} \times 1 \mathrm{~m}$, 219 where the point clouds belonging to vegetation were removed 220 by visual inspection in Terrscan environment. Due to the in221 frared wavelength of $1064 \mathrm{~nm}$ operated by the ALTM 3070, 222 water absorption prevents ALS measurement for underwater 223 surfaces. The underwater elevations were thus measured using 224 a total station and surveying prism pole in wadable areas, while 225 a shipboard single-beam SONAR was used to survey deeper 226 areas in June 2009. To facilitate the integration of a complete 227 DEM of the study area, all surveying, including ALS, was 228 referenced to TWD97 datum, the national coordinate system 229 of Taiwan. The DEMs of the wet surfaces of a resolution of $2301 \mathrm{~m} \times 1 \mathrm{~m}$ were interpolated from total station and SONAR 231 data. The complete DEM of the study area was created by 232 mosaicking the two DEMs of the dry and wet surfaces, respec233 tively, and was further used for hydrodynamic modeling.

\section{B. Hydrodynamic Modeling}

235 To explore the relation between the ALS-derived PCDs and 236 flow directions, we simulated the depth-averaged 2-D flow 237 fields under high- and low-flow scenarios using a finite-element 238 (FE) hydrodynamic model developed by $\mathrm{Wu}$ et al. [28]. The 239 computational domain, extending $600 \mathrm{~m}$ to the Hsintien Creek 240 and 700 and $500 \mathrm{~m}$ to the NanShih and PeiShih Creeks 241 [Fig. 2(a)], contained 17105 elements and 9000 nodes with a
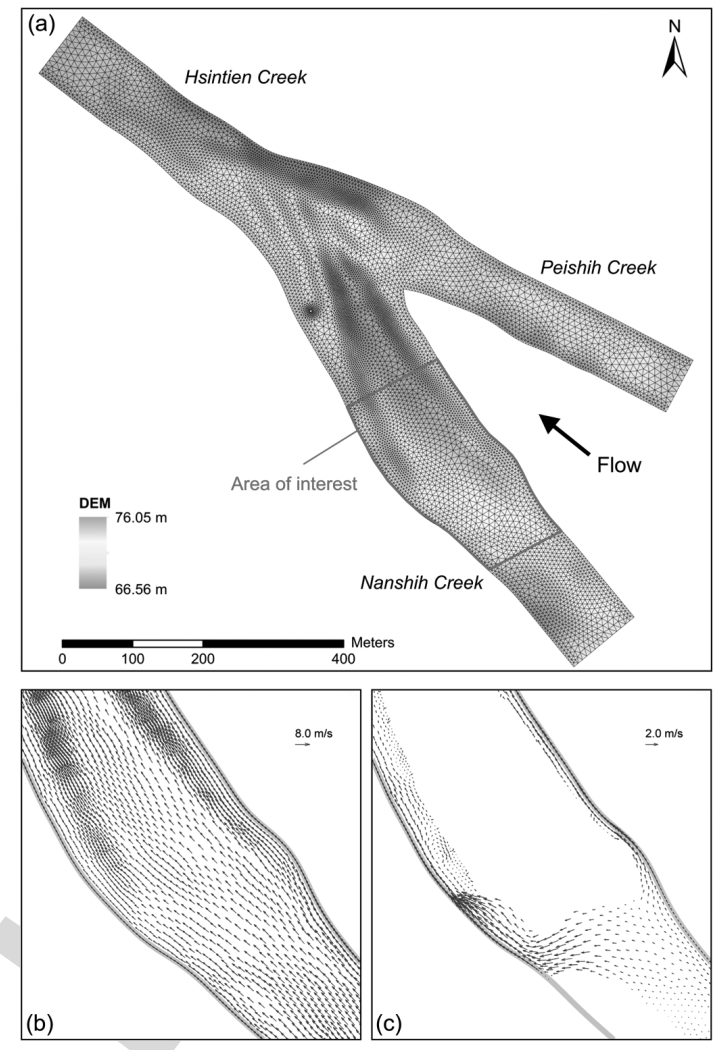

Fig. 2. (a) ALS-derived DEM map and computational mesh of simulation domain, which extends $600 \mathrm{~m}$ to the Hsintien Creek and 700 and $500 \mathrm{~m}$ to the NanShih and PeiShih Creeks, and contains 17105 elements and 9000 nodes with a mean spacing of $4 \mathrm{~m}$; simulated velocity vectors under (b) high-flow and (c) low-flow scenarios, where the regions without velocity data are exposed bars. The scenario simulations exhibit different extents of bar submergence and distinct patterns of 2-D flow field.

mean spacing of $4 \mathrm{~m}$. The ALS-derived DEM was mapped 242 to the FE grids via a triangulated irregular network shown in 243 Fig. 2(a). The model was validated with the observed water lev- 244 els [29]. The calibrated parameter values were then used for the 245 scenario simulations. The upstream boundary conditions (BC) 246 were specified with the flows from the NanShih and PeiShih 247 Creeks, while the downstream BC was specified with the water 248 depth at the Hsintien Creek. For the high-flow scenario, the 249 specified flows (3400 and $1230 \mathrm{~m}^{3} \mathrm{~s}^{-1}$ ) are equivalent to a flood 250 event with seven-year return period; for the low-flow scenario, 251 the specified values (23 and $18 \mathrm{~m}^{3} \mathrm{~s}^{-1}$ ) correspond to flows 252 with a $50 \%$ probability of exceedance. These two scenario 253 simulations exhibited different extents of bar submergence and 254 distinct patterns of 2-D flow field [Fig. 2(b) and (c)]. The 255 simulated velocity vectors at the FE nodes were interpolated 256 to the centers of the $6 \mathrm{~m} \times 6 \mathrm{~m}$ ALS subset, allowing direct 257 comparisons of the ALS-derived PCDs and flow directions. 258

\section{RESUlTS AND DisCUSSION}

\section{A. Anisotropy Property of $2 \mathrm{DVSs}$}

The 2DVSs of the 324 ALS $6 \mathrm{~m} \times 6 \mathrm{~m}$ subsets were com- 261 puted using the R software, and the contour map of the 2DVS 262 was generated using a purpose-written MATLAB program. 263 Based on internal testing, the lag distance of the 2DVS and the 264 contour level interval in the contour plot were set to $15 \mathrm{~cm}$ and 265 0.05 , respectively, to best reveal anisotropic structures. 
(a)

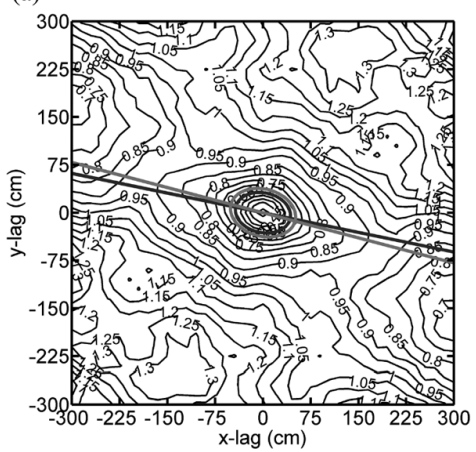

(b)

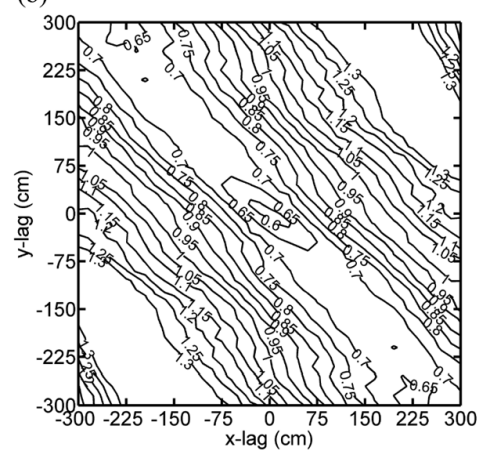

(c)

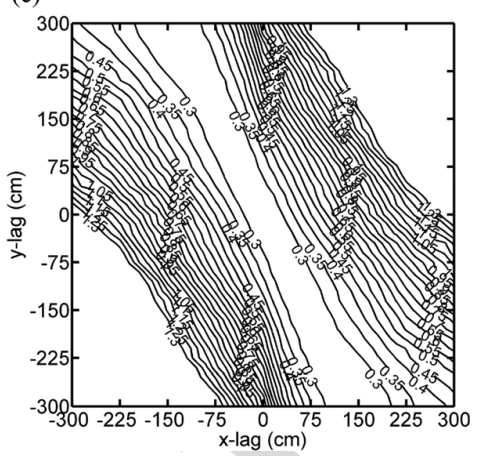

Fig. 3. (a) Contours of the 2DVS reveal a clear anisotropic structure. The ellipse-fitting procedure was applied to the black and gray contour, respectively, in order to determine the PCDs. The black and gray lines are the PCDs determined from the fitted ellipse with the semimajor axis lengths equal to $8.0 d_{50}$ and $9.5 d_{50}$, respectively. The contours of the 2DVS in (b) and (c) show a clear anisotropic structure, but there exist only parallel contours in (c), which prevents application of the ellipse-fitting procedure to obtain the PCD.

267 Most of the 2DVSs of the ALS $6 \mathrm{~m} \times 6 \mathrm{~m}$ subsets revealed 268 a clear anisotropic structure similar to the contours shown 269 in Fig. 3(a). It is thus appropriate to apply the ellipse-fitting 270 procedure to a specific contour to determine the PCD. While a 271 small number of subsets show fewer [Fig. 3(b)] or no [Fig. 3(c)] 272 elliptical contours in their 2DVS, the anisotropic structure is 273 still prominent. Based on visual inspection, the 2DVSs similar 274 to Fig. 3(b) and (c) appeared to be in the area covered by silt and 275 gravel, which is highlighted by the white rectangle in Fig. 1(a). 276 Due to the requirement of ellipse fitting, the ALS-derived PCDs 277 are only available for those 2DVSs similar to Fig. 3(a) and (b).

\section{B. Determination of ALS-Derived PCDs}

279 To mitigate the influence of the jagged appearance of the 280 elliptical contours with small lag distances [c.f., Fig. 3(a)] on 281 the PCD estimation, we applied the ellipse-fitting procedure 282 only to those contour lines including more than 20 cells in the 283 2DVS, which implies that the semimajor axis length of the fitted 284 ellipse should be larger than $7 d_{50}$ in our study area.

285 When there are more than two candidate contour lines that 286 fall in a range of multiple times of $d_{50}$, we select the PCD 287 with the smallest semimajor axis length. As shown in our data, 288 the difference between different PCDs is insignificant. Fig. 3(a) 289 shows an example for the determination of the PCD with the 290 semimajor axis length constraint being 7-10 $d_{50}$, and two 291 candidate contours with their semimajor axis lengths of $8.0 d_{50}$ 292 [black line in Fig. 3(a)] and $9.5 d_{50}$ [gray line in Fig. 3(a)] 293 were found, where the former one would be reported. The angle 294 difference between these two PCDs is as small as $3^{\circ}$.

295 To further examine the insignificance of PCD bias caused by 296 the choice of semimajor axis length constraint in the ellipse fit297 ting, we generated three sets of ALS-derived PCDs determined 298 from the semimajor axis length within three ranges, i.e., $7-10 d_{50}$, 299 9-12 $d_{50}$, and 11-14 $d_{50}$, and compared these PCD results with 300 the simulated high- and low-flow directions. The choice of these 301 constraint ranges was made in order to maximize of chance of 302 having at least one available contour for each constraint.

\section{C. Comparison of ALS-Derived PCDs and Simulated} 304 Flow Directions

305 The angle differences of the ALS-derived PCDs and simu306 lated flow directions were calculated. The positive angle dif-
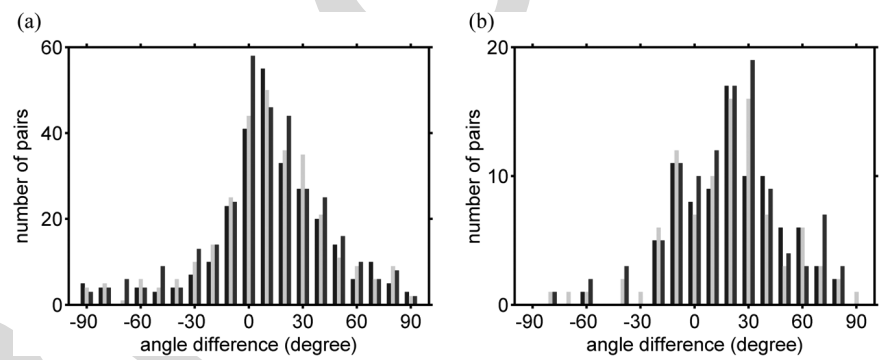

Fig. 4. Histograms of the angle differences between the three sets of ALSderived PCDs and simulated flow directions at (a) high and (b) low flow. The red, green, and blue bins represent the histograms of the angle differences calculated from the three sets of ALS-derived PCDs determined by the semimajor axis length constraints, which are 7-10 $d_{50}, 9-12 d_{50}$, and $11-14 d_{50}$, respectively.

ferences denote that the ALS-derived PCD lies to the left of 307 the simulated flow directions when facing downstream; the 308 negative angle differences denote that the ALS-derived PCD 309 lies to the right of the simulated flow directions. 310

The histograms of the angle differences for high and low 311 flow are shown in Fig. 4(a) and (b), respectively. The red, 312 green, and blue bins in Fig. 4 represent the histograms of the 313 angle differences calculated from the three sets of ALS-derived 314 PCDs determined by the semimajor axis length constraints 315 being 7-10 $d_{50}, 9-12 d_{50}$, and 11-14 $d_{50}$, respectively. For the 316 high flow, the total numbers of comparison pairs are 324, 299, 317 and 275 when the semimajor axis constraints are 7-10 $d_{50}, 318$ 9-12 $d_{50}$, and 11-14 $d_{50}$, respectively; for the low flow, the total 319 numbers of comparison pairs become 107, 96, and 89 when 320 the semimajor axis constraints are 7-10 $d_{50}, 9-12 d_{50}$, and 321 11-14 $d_{50}$, respectively. Because the submerged area is much 322 smaller for low-flow condition [c.f., Fig. 2(c)], the number of 323 comparison pairs for low flow was much less than that for high 324 flow. Furthermore, we noted that the number of available ALS- 325 derived PCDs decreased with the increase of the semimajor 326 axis length constraint. Because the semivariances of 2DVS are 327 expected to increase slowly at large lag distances [1], [26], 328 the larger spacing of contours in the 2DVS leads to fewer 329 contours available for ellipse fitting. As observed in Fig. 3(a), 330 the elliptical contours starting from 0.5 to 0.9 become sparse. It 331 is also noted that the contours became fragmented, and it was 332 not easy to find ellipse shape [as shown in the upper left and 333 lower right corner in Fig. 3(a)] when the data are not able to 334 reveal such long range spatial correlation in the 2DVS. 
(a)

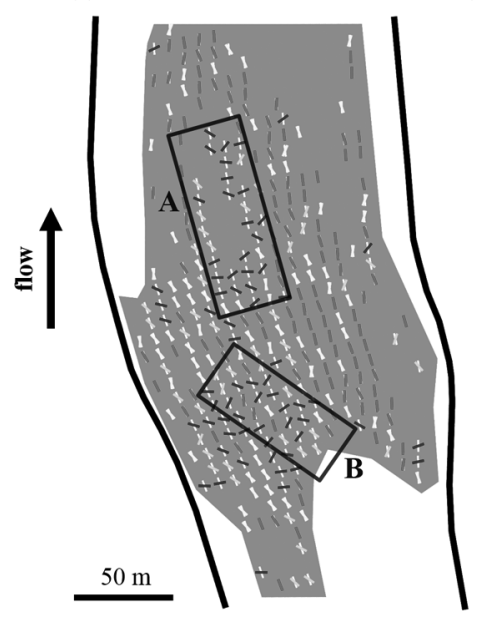

(b)

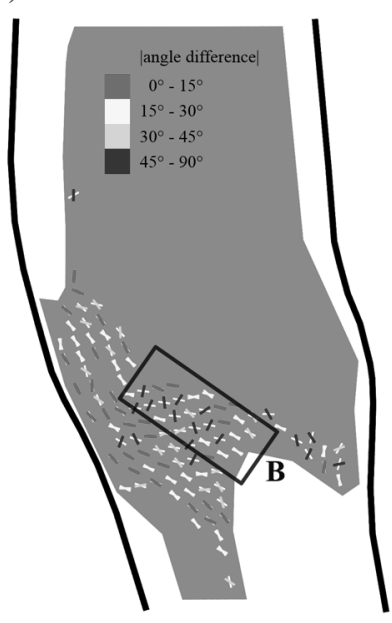

Fig. 5. Comparison of the ALS-derived PCDs and simulated flow directions at (a) high and (b) low flow. The gray polygon is the extent of the exposed gravel bed. The white segments represent the simulated flow directions. The red, yellow, green, and blue segments denote the absolute values of angle difference of $0^{\circ}-15^{\circ}, 15^{\circ}-30^{\circ}, 30^{\circ}-45^{\circ}$, and $45^{\circ}-90^{\circ}$, respectively, of the ALS-derived PCDs with respect to simulated flow directions. Rectangle A denotes the area with notable discrepancies of ALS-derived PCDs and highflow direction. Rectangle B denotes the area where the ALS-derived PCDs have better agreement with low-flow direction than high-flow direction.

336 As observed in Fig. 4, the distributions of the angle differ337 ences with three different semimajor axis constraints for high 338 and low flow are, respectively, similar. To further demonstrate 339 the similarity between each distribution of angle difference, 340 for high and low flow, respectively, we applied the nonpara341 metric Kruskal-Wallis test, implemented in R software. The 342 null hypothesis for the Kruskal-Wallis test is that the three 343 sets of angle differences come from the same distribution. The 344 resultant $p$-values for the Kruskal-Wallis test are 0.89 and 0.83 345 for high and low flow, respectively, both of which failed to reject 346 the null hypothesis at the significant level of 0.05 . This implies 347 that the angle differences calculated from the three sets of 348 ALS-derived PCDs and simulated flow directions do not reveal 349 statistically significant differences. It is thus suggested that the 350 ALS-derived PCDs derived from any elliptical contour of the 351 2DVS should exhibit similar orientation when the contours 352 of the 2DVS reveal the clear anisotropic structure. The ALS353 derived PCDs determined with the semimajor axis length con354 straint of $7-10 d_{50}$ are discussed as it gave the largest number 355 of comparison pairs.

356 Fig. 5(a) and (b) demonstrates the comparison of ALS357 derived PCDs and simulated high- and low-flow directions, 358 respectively. The gray polygon in Fig. 5 shows the extent 359 of exposed gravel bed [also shown as the black polygon in 360 Fig. 1(a)]. The white segments in Fig. 5 represent the simulated 361 flow directions. We observed that the simulated flow directions 362 for high flow are primarily parallel to the main stream direc363 tion in Fig. 5(a). Moreover, the simulated low flow primarily 364 flows through the temporarily submerged area in Fig. 5(b) 365 [c.f., the gray rectangle in Fig. 1(a)]. The red, yellow, green, 366 and blue segments in Fig. 5 denote the absolute values of 367 angle difference of $0^{\circ}-15^{\circ}, 15^{\circ}-30^{\circ}, 30^{\circ}-45^{\circ}$, and $45^{\circ}-90^{\circ}$, 368 respectively, of the ALS-derived PCDs with respect to simu369 lated flow directions.

We noted a good agreement between the ALS-derived PCDs 370 and simulated high flow in the right portion of the exposed 371 gravel bar [Fig. 5(a)], where the white segments become invis- 372 ible due to the insignificant angle difference between the ALS- 373 derived PCDs and simulated high flow. This implies a potential 374 for inferring high-flow direction from ALS-derived PCD for 375 this area. However, an area with notable discrepancies of the 376 ALS-derived PCDs and high-flow direction is also presented 377 [denoted as rectangle A in Fig. 5(a)]. For the temporarily 378 submerged gravel bed area, we observed that the ALS-derived 379 PCDs showed better agreement with the simulated low-flow 380 direction than the high-flow direction [where a larger number 381 of red and yellow segments are found in Fig. 5(b)], expect for 382 the rectangle $\mathrm{B}$ area.

Furthermore, Fig. 4 reveals that the angle differences at high 384 flow exhibit a peak close to $0^{\circ}$, while at low flow, the peak is 385 close to $30^{\circ}$, which suggests that the PCDs of bed surface struc- 386 ture are, overall, better correlated to the high flow. However, for 387 the topographically low spots (e.g., rectangle B in Fig. 5), the 388 low flow might have left a signature on the bed surface during 389 the recession of flood, where the PCDs are better correlated 390 to the low flow. From the aforementioned results, we demon- 391 strated that the ALS-derived PCDs correspond to the flow 392 directions at different flow rates.

393

It is noted that the typhoon-induced torrents were 3-D turbu- 394 lent flows, typically characterized by fluctuating velocities with 395 their magnitudes and directions changing with time and depth 396 [30]. However, the 2-D hydrodynamic simulation performed 397 herein was based on steady depth-averaged flood flows; thus, 398 the discrepancies between the PCDs of bed surface structure 399 and the computed flow directions may be attributable in part to 400 these unresolved spatial variations.

401

\section{CONClusion}

In summary, we have explored the relationship of the aniso- 403 tropy direction of exposed gravel bed (i.e., the ALS-derived 404 PCDs) and simulated flow directions. We have determined the 405 PCDs from the 2DVSs by applying an ellipse-fitting procedure 406 with consideration given to the grain size characteristic $d_{50} .407$ The angle differences between the ALS-derived PCDs and sim- 408 ulated flow directions were calculated, and the Kruskal-Wallis 409 test was performed on the angle differences. The results suggest 410 that the ALS-derived PCDs estimated from any elliptical con- 411 tour of the 2DVS should exhibit similar orientation when the 412 contours of the 2DVS reveal a clear anisotropic structure. Fur- 413 thermore, the comparison of the ALS-derived PCDs and sim- 414 ulated flow directions shows good agreement, which suggests 415 that ALS-derived PCDs could be used to infer flow direction at 416 different flow rates.

417

What is remarkable here is that the process for determining 418 the PCD in the 2DVS is largely automatic and is scalable. Here, 419 we applied the technique to 324 ALS $6 \mathrm{~m} \times 6 \mathrm{~m}$ subsets, but 420 potentially, this is expandable and scalable to the whole ALS 421 scenes where the river can be adequately demarcated. Thus, this 422 letter points to the potential of determining flow direction across 423 large areas, at both high and low flow, without the need for 424 in situ measurement or simulation modeling. Future research 425 should demonstrate this ability across a range of different flow 426 conditions and for a wider range of gravel bed surfaces. 


\section{REFERENCES}

1] P. Goovaerts, Geostatistics for Natural Resources Evaluation. London, U.K.: Oxford Univ. Press, 1997.

[2] R. Mott, M. Schirmer, and M. Lehning, "Scaling properties of wind and snow depth distribution in an alpine catchment," J. Geophys. Res. Atmos., vol. 116, no. D6, Mar. 2011, Art. no. D06106, doi: 10.1029/ 2010JD014886.

[3] J. Aberle and V. Nikora, "Statistical properties of armored gravel bed surfaces," Water Resour. Res., vol. 42, no. 11, Nov. 2006, Art. no. W11414, doi: 10.1029/2005WR004674.

4] J. B. Butler, S. N. Lane, and J. H. Chandler, "Characterization of the structure of river-bed gravels using 2D fractal analysis," Math. Geol., vol. 33, no. 3, pp. 301-330, Apr. 2001.

[5] R. Hodge, J. Brasington, and K. Richards, "Analysing laser-scanned digital terrain models of gravel bed surfaces: Linking morphology to sediment transport processes and hydraulics," Sedimentology, vol. 56, no. 7, pp. 2024-2043, May 2009.

6] J. Qin, D. Zhong, G. Wangm, and S. L. Ng, "Influence of particle shape on surface roughness: Dissimilar morphological structures formed by man-made and natural gravels," Geomorphology, vol. 190, pp. 16-26, May 2013.

7] P. E. Carbonneau, S. N. Lane, and N. E. Bergeron, "Cost-effective non-metric close-range digital photogrammetry and its application to a study of coarse gravel river beds," Int. J. Remote Sens., vol. 24, no. 14, pp. 2837-2854, Jul. 2003.

[8] G.-H. Huang and C.-K. Wang, "Multi-scale geostatistical estimation of gravel-bed roughness from terrestrial and airborne laser scanning," IEEE Geosci. Remote Sens. Lett., vol. 9, no. 6, pp 1084-1088, Nov. 2012.

[9] P. K. Kitanidis, Introduction to Geostatistics Applications in Hydrogeology. Cambridge, U.K.: Cambridge Univ. Press, 1997.

0] J. Schlee, "Fluvial gravel fabric," J. Sedimentary Petrol., vol. 27, no. 2, pp. 162-176, 1957.

1] D. J. Douglas, "The structure of sedimentary deposits of braided rivers," Sedimentology, vol. 1, no. 3, pp. 167-190, Sep. 1962.

C. E. Johansson, "Orientation of pebbles in running water: A laboratory study," Geogr. Ann. A, vol. 45, no. 2/3, pp. 85-112, 1963.

3] G. Kelling and P. F. Williams, "Flume studies of the reorientation of pebbles and shells," J. Geol., vol. 75, no. 3, pp. 243-267, May 1967.

B. R. Rust, "Pebble orientation in fluvial sediments," J. Sedimentary Petrol., vol. 42, no. 2, pp. 384-388, Jun. 1972.

] M. E. Kauffman and D. F. Ritter, "Cobble imbrication as a sensitive indicator of subtle local changes in river flow direction," Geology, vol. 9, no. 7, pp. 299-302, Jul. 1981.
[16] R. P. Millane, M. I. Weir, and G. M. Smart, "Automated analysis of im- 472 brication and flow direction in alluvial sediments using laser-scan data," 473 J. Sedimentary Res., vol. 76, no. 8, pp. 1049-1055, Aug. 2006.

[17] J. B. Laronne and M. A. Carson, "Interrelationships between bed mor- 475 phology and bed-material transport for a small, gravel-bed channel," 476 Sedimentology, vol. 23, no. 1, pp. 67-85, Feb. 1976.

[18] S. Bertin and H. Friedrich, "Field application of close-range digital pho- 478 togrammetry (CRDP) for grain-scale fluvial morphology studies," Earth 479 Surf. Process. Landforms, to be published, doi: 10.1002/esp.3906.

[19] G. Smart, J. Aberle, M. Duncan, and J. Walsh, "Measurement and analysis 481 of alluvial bed roughness," J. Hydraulic Res., vol. 42, no. 3, pp. 227-237, 482 2004.

[20] L. Mao, J. R. Cooper, and L. E. Frostick, "Grain size and topographical 484 differences between static and mobile armour layers," Earth Surf. Process. 485 Landforms, vol. 36, no. 10, pp. 1321-1334, Aug. 2011.

[21] R. M. Westaway, S. N. Lane, and D. M. Hicks, "Remote survey of large- 487 scale braided, gravel-bed rivers using digital photogrammetry and image 488 analysis," Int. J. Remote Sens., vol. 24, no. 4, pp. 795-815, 2003.

[22] A. S. Woodget, P. E. Carbonneau, F. Visser, and I. P. Maddock, "Quantify- 490 ing submerged fluvial topography using hyperspatial resolution UAS im- 491 agery and structure from motion photogrammetry," Earth Surf. Process. 492 Landforms, vol. 40, no. 1, pp. 47-64, Jan. 2015.

[23] A. D. Tamminga, B. C. Eaton, and C. H. Hugenholtz, "UAS-based remote 494 sensing of fluvial change following an extreme flood event," Earth Surf. 495 Process. Landforms, vol. 40, no. 11, pp. 1464-1476, Sep. 2015.

[24] J. Hohenthal, P. Alho, J. Hyyppä, and H. Hyyppä, "Laser scanning appli- 497 cations in fluvial studies," Progr. Phys. Geogr., vol. 35, no. 6, pp. 782-809, 498 Dec. 2011.

[25] "Titan Multispectral Lidar System Datasheet," Teledyne Optech Inc., 500 Kiln, MS, USA, Accessed Mar. 15, 2016. [Online]. Available: http:// 501 www.teledyneoptech.com/wp-content/uploads/Titan-Specsheet-150515- 502 WEB.pdf

[26] E. H. Isaaks and R. M. Srivastava, Applied Geostatistics. New York, NY, 504 USA: Oxford Univ. Press, 1989.

[27] D. J. Graham S. mated grain sizing of river gravels," Water Resour. Res., vol. 41, Jul. 2005, 507 Art. no. W07020, doi: 10.1029/2004WR003868.

[28] F.-C. Wu, Y.-C. Shao, and Y.-C. Chen, "Quantifying the forcing effect of 509 channel width variations on free bars: Morphodynamic modeling based 510 on characteristic dissipative Galerkin scheme," J. Geophys. Res., vol. 116, 511 Sep. 2011, Art. no. F03023, doi: 10.1029/2010JF001941.

[29] "Planning Report for Training of Upstream," Water Resour. Agency 513 (WRA), New Taipei, Taiwan, 2009.

[30] J. S. Bridge, Rivers and Floodplains: Forms, Processes, and Sedimentary 515 Record. Hoboken, NJ, USA: Wiley-Blackwell, 2003. 


\section{AUTHOR QUERIES}

\section{AUTHOR PLEASE ANSWER ALL QUERIES}

The paper exceeds the maximum allowable number of pages. Please shorten the paper to fit into five pages.

Please be aware that authors are required to pay overlength page charges ( $\$ 200$ per page) if the paper is longer than 3 pages. If you cannot pay any or all of these charges please let us know.

This pdf contains 2 proofs. The first half is the version that will appear on Xplore. The second half is the version that will appear in print. If you have any figures to print in color, they will be in color in both proofs.

The "Open Access" option for your paper expires when the paper is published on Xplore in an issue with page numbers. Papers in "Early Access" may be changed to "Open Access."

AQ1 = Please check if there is a need to change "expect" to "except."

AQ2 = Please provide publication update in Ref. [18].

END OF ALL QUERIES 